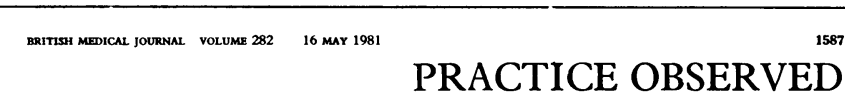

\section{Law and the General Practitioner}

\section{Appearing in court}

BERNARD KNIGHT

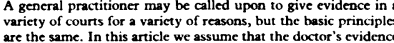 is in relation to his professional activities and not to some non-
medical happening such as witnessing a rovad accident, where
his sanding in his standing in court will be the same as any other member of
the public. In his professional capacity the gencral practitioner, unless a
police surgeon, will seldom act as an expert witness. This is
usually the role of the consultant pathologist or surgeon whe appears in court to interpret and give opinions on postmortem
findings or the prognosis of a dissobled patient. Most of the
find Iegal pronouncements of family doctors will concerm matters of
medical fact arising out of their practice, though there is $\mathbf{a}$ somewhat indistinct zonc between this aspect and an opinio
upon thoses same facts, which then merges into the purview of
the expert witness.}

Appearing as a professional witnese

Let us concentrate for the moment, however, on the most
common activity when the docior appecars as a " profession witness." This term distinguishes him both from the lay
citizen who is giving purcely exe-winess accounts of what he
saw and from the expert who offen pontificates upon cases that

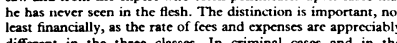
different in the three classes. In criminal cases and in the
coroner's courts ffers are rigitly laid down and the " "going rate"

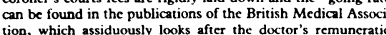

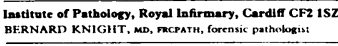

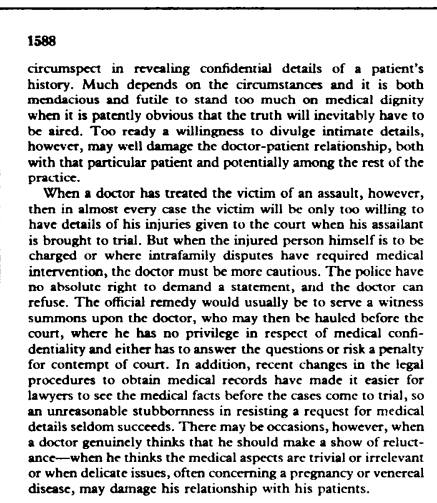

In civil matters, particularly those concerning compensation
for dissbility after accictents and industrial injuries, the prac-
titioner must be wary of requests from solicitors for areport on

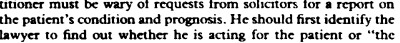

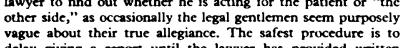

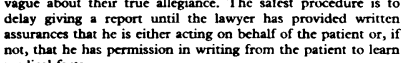
not, that he has permission in writing from the patient to learn
medical facts.
When the doctor is sarisfied that be is able to give the statement, this should be accurrate, concisis, and confined to matters
of medical fact, free from any conjecture or opinions unless these

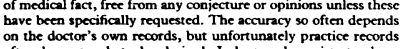
on the doctor's sown records, but unfortunately practice record
often leave much to be desired. Judges and magistrates have
many times waxed caustic over the apparent medical amnessia

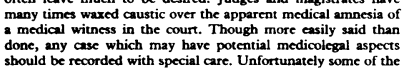
done, any case which may have potential medicolegal aspects
sbould be recorded with special acre. Unfortunately some of the
apparenty most humdrum events lead to weighty forensic apparently most humdrum events lead to weighty forensic
consequences and, as these may socur months or even years
later, the memory of the doctor for the details may be as blank
as his record card.

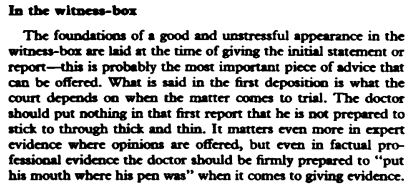

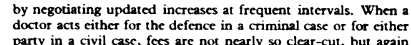
are not nearly so clear-cut, but again

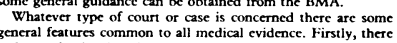
is the mefhanism by which the doctor beromes embroiled in the wholc affair, oficn reluctantly. The first approach may be made
by a police officer, when the case is to be heard before either a statutory duty on all citizens, doctors included, not to hamper he coroner in his investigation. No problems about medical
confidentiality cxist when the paticnt is dead, and indecd it is
often the doctor who initiates the whole affiar by first reporting often the doctor who initiates the wholc affair by first reporting
the casc to the corroner. the cass to the coroner.
In any cvent the police officer or coronect's officer will ask for a statement about the medical history and the events of the deat
and if an inquest is held, the doctor may well be required to
atuend and give his cvidence. In the coroner's court the proacend and give his evidence. In the coroner's court the pro-
ceedings are informal, and though lawyers may be present the
srict rules of evidence seen in other courts do not apply so that sedings are informal, and hough lawyers may be present the
stric tules of evidence seen in oher courst do not apply so that
the tenor of the procecedings is usually more relaxed. After either reading his statement or being led through it by
the coroner, the doctor may be asked questions by the relatives, are keenly aware ef the demands on a general practitioner's time
and will usuanlyy e either call the doctor carly in the case and for him to attend at some predetes gined tive. Comparad with the formality of the Crown Courts, siving evidence at an inquess
is no ordeal at all, if the doctor has taken the trouble to provide is no ordeal at all, if the doctor has taken the trouble to provice
a coherent statement and has read it over before stepping into
he witness-box the witness-box.
When the matrer concerns a live patient and is to go before the
magisistrates or Crown Court, then the doctor needs to be more coroner or a criminal courr. This may escalate from quitc
innocuous beginnings, the policeman initially asking merely for
statement about the doctor's dealings with a patient. Wher

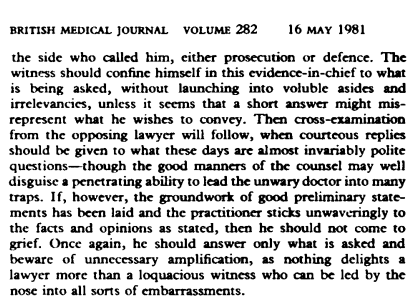

NO BOMBSHFLUS OR JARGON

The doctor is there to help the court and to assist in arriving
at the truth, whatever that may be. He should therefore not be overtly partisan on behalf of "his side" and not reply evasively,
belligetrently, or recluctantly when questioned by the adversary lawyer. He has an echical duty not to conceal any facts which
may be addanagageus to the cother side, though he should not
voluntect facts not brought out by his own counscl unless it is

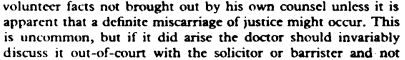

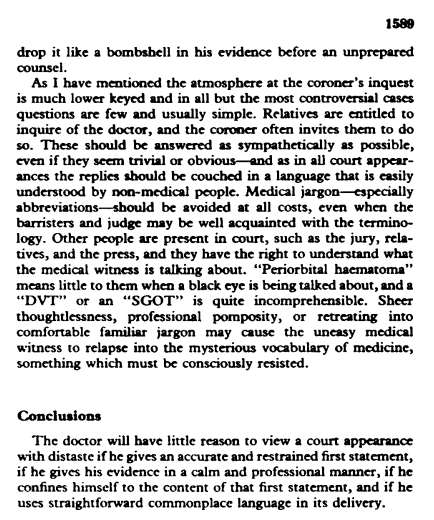

\title{
Sex Problems in Practice
}

\section{Referring patients to a gynaecologist or psychiatrist and} to a marriage guidance counsellor

PHILIP R MYERSCOUGH, ANITA BLUM

Consultant kynaecologist or psychiatrist

BRTISH MEDDCAL JOURNAL VOLUME $282 \quad 16$ MAY 1981

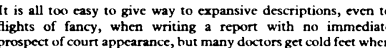
prospect of court appecarance, hut many doctors get cold feet when
the day of the hearing approaches and they try to back of frum what they had put their signatures to some months previously.
This fault of " "not coming up to proof," "s the lawyers call tit is

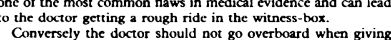
Conversely the doctor should not go overboard when giving
his evidence, so that he makes sweeping statements and intro-
duces new facts that he never mentioned in his statement. He risks being tied in knots by the opposing lawyers, who are adept
at digging large verhal hoies into which the garrulous witness
readily falls. It cannot te overemphasised that the sereneity or
otherwise of the appearance in court depends largely on the readily falls. It cannot be overemphasised that the serenity
otherrise of the appearance in courr depends largely on the
foundation laid by the original statement.

ACTS AND OPINIONS

As mentioned carlicr, mosit family doctors will go to court to
give factual accounts of their dealings with a paticnt rather than give the morce expert task of drawing conclusions from those
facts. It is offen impossible, howcerer, to draw a strict line of nay describe how he sutured a wound on a person's scalp, whic is a matter of fact. But then he may reasonatly be asked whecher
he wound was serious and whether he considered that it the wound was scrious and whether he considered that i
constituted any risk to life. This then becomes $a$ matter of opinion, based on clinical experience and judgment. Similarly a
doctor may relate facts of a patient's sermatitis in respect of the an opinion, and the doctor should accept these minor excursions
into such marginal areas of expertise. If the questioning gocs more deeply into matters of opinion, however, he should either resist the trend by stating plainly that he does not feel compterent
cnough to hazard expert opinions or point out to magistratc or udge that he is now being asked to act as an expert witness-
with a conseguent increasc in his fee. He should only do this if $h e$ with a consequent increase in his feer. He should only do this if he
feels on sure ground that his opinion is justified. He might be ar aetter qualified, for instance, to give an obstetrical opinice irith for 30 y yars, but a ganceral practitioner would be il advised to trespass far into felds such as orthopacdics or surgery.
In fact he mingt well be challenged prety smarly by the
opposing lawyer as to his competence in such fields.

AIR OF QUIET AUTHORIT

As to actual courtroom technique, nothing can surpass a cool
and reasoned statement of the facts, given in a profossional

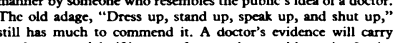
much more weight if it comess from a witeress with an air of quier auchority- hece general demeanour and appearance certainly help
in establishing this image. Even in thesc days of rampant

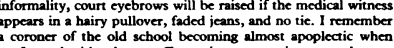
a coroner of the old school becoming almost appoplectic when
confronted with a housc-officer witesess at an inquest, who was confronied with a house-officer witness at an inquest, who was
dressed in a Stetson and a louti, pleid lumberiacter. The
dissomfited doctor was dismissed from the court to return in

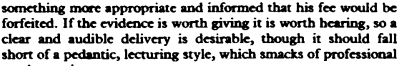
ondescension.
In cours other than the coroner's, the doctor will usually be
led through his evidence by the berrister or solicitor acting for permission- -iver and cakes responsibility for change in this
ureament which is highly goal-oniented.
Six counsellors were trained in thesc methods in the Midlands
The pattern of referral for sexual problems varies from place
to place, depending on the services avaiable and the skills and
intersss of individuals, who may belong to one of

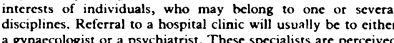
by the patient as having very different roles, and they usuall
function within different frameworks. To simplify, the gyna function within different frameworks. To simplify, the gynae-
cologisit's skills include intimate touching, which is profession-
alised partly by not focusing upon sexuality, whereas the

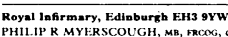

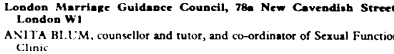

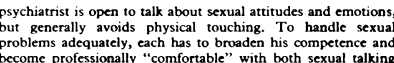
and sexual touching.
In deciding when to refer problems to one or the other, the eneral practitioner will obviously be influenced by his local
nowledge of an individual's skills. The following guidelines PATIENTS SUITABLE POR GYNAECOLOGICAL REFERRAL Patients with dyspareunia as a primary problem should
always undergo a carcful and skilled cxamination to identify ocal causes-for example, vaginitis, tender scars or carunculac, urechrins, or pelvic iniammatory discease. Indece, all women whe
find intercourse painful thould, in my view, have a pelvic
examination, even if this is only to reassure them that they are

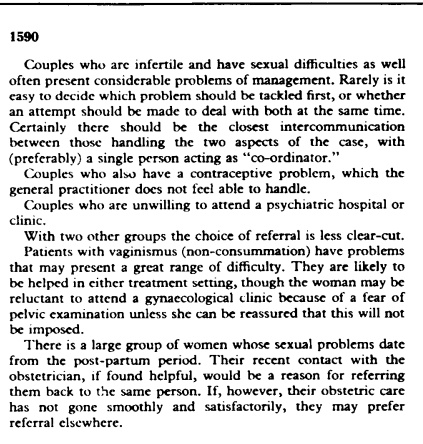

PATIENTS SUITABLE FOR PSYCHATRIC REFERRA

Patients who also have a problem of sexual orientation
(homosexuality, bisexuality) or of sexual identity (transsexuality). (homosexuality, bisexuality) or of sexual identity (rranssexuality).
Patients with octer paraphilis.
Patients whose pattern of general behaviour is so abnormal as to suggest a personality disorder.
Patients whose sexual difficulties are accompanied by morbid Paticnts whose sexual difficulties are accompanied by morbid
depression or sustained anxiety.
Paxients whose sexual problems are complicated by alcohol Patients whose
other drug abuse

Finally there are couples whose sexual difficulties are only a.
part of b brader problem within the whole marital rectationship. pschiartic clinic, althoungh other ragencies, such as the Marriage
Counselling Service and social workers, may be available to provide this type of treatment.

London Marriage Guidance Council

In 1974 the Department of Health gave a grant to the National
Marriage Guidance Council (NMIGC) to train a few counselloas

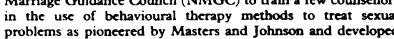
by Helen Singer Kaplan. The skills of these experienced
counsellors - who had completed the two-year absic training and counsellors-who had completed se tervisior that the NMGGC
receive in-service training and supervision
provides for all counsellors- would be an excellent foundation limited behavioural methord for specific sexual dysfunctions
Counselling is concerned with helping a couple to understan

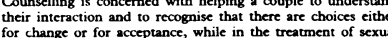

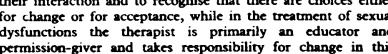
BRITISH MEDICAL JoURNAL volume $282 \quad 16$ MAY 198 and the results of this three-year experiment encouraged the
DHSS to give a further grant 5 thet the thraining could be spread throughout the country. There are now about 30
clinics. Adresses of clinisty

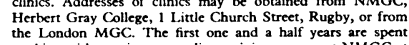
working with a trainer, attending training courses at NMGGC at
Rugbty, and attending regular case discussion groups. The
secend year and a half is spent in co-therapy with a peer, or in

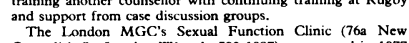
Cavendish $\mathrm{St}, \mathrm{Lndon} \mathrm{W}_{1}$, tel: $580-1087$ ) was started in 1977
and now offers 14 sessions a week, run by six trained therapists

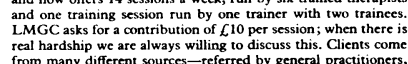

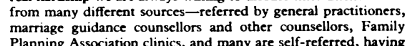
marrage guidance counsellors and ay are self-referred, having
Planning Association clinics, and mant
heard of the clinic through the media. Treatment is offered only to couples in a commititer relationship, and, due to the experi-
mental nature of the treatment, cannot be offered to individuals.

In the first interview the therapist determines whether the presenting problem is primarily a sexual onc or is the presenting
symptom of dece undertying oofficts in the pyschopathology
of the individuals or of their relationship. When it seems that of the individuals or of their relationship. When it seems that
the latter may interfere with treament the couple are usually
advised to seck counselling first. A retrospective analysis of advised to seck counselling first. A retrospective analysis of
couples who werc assessed and treated during the first two years correct assesssmont made at this stage of the balance between the
"psycho" and the "sexual" components of the problem, the "psycho" and the "sexual" components of the problem, the
former carrying the poorer prognosis. This scems slaso to be the

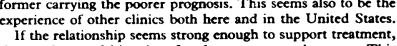
If the relationship seems strong enough to support treatment,
the psychosesual histories of each parnera are taken next. This he psychosexual histories of each partser are taken next. This
is followed by a "round table" session when a contract is built
between therapist and clienes based on mutually agreed aims. between therapist and clients based on mutually agrced aims.
The treatment is explained in further decail and the first sensatc
focus exercises are set. The treatrentent then becomes tailor-made

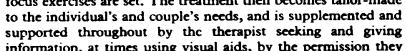
supported throughout by thc therapist secking and giving
information, at times using visual aids, by the permission they
ive to the clients to be sexual and, above all, by the therapist's give to the clients to be sexual and, above all, by the therapist's
feeling comfortable in the area of sexuality. Deeper problems

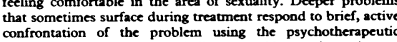
approach of counselling to challenge or sidestep the resistance
to the purcly behavioural methods. A balance and flexibility o the purcly behavioural methods. A balance and flexibility
between these two methods is essential in each case. Treatment lasts on average between 8 and 14 weckly selssions.
Success measured in terms of oupples walking of happinto
he sunset is rare, but it does happen, and success in terms of 8 the sunset is rare, but it
much improved sexual
a greatly improved relationt greatly improved relationship in general.
The following dysfunctions are treated in the clinic: Men.

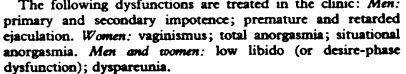

